\title{
Cyclopamine functions as a suppressor of benign prostatic hyperplasia by inhibiting epithelial and stromal cell proliferation via suppression of the Hedgehog signaling pathway
}

\author{
YI-FENG YUAN $^{1}$, WEN-XIONG ZHU ${ }^{1}$, TAO LIU ${ }^{1}$, JU-QIAO HE ${ }^{1}$, \\ $\mathrm{QING}_{\mathrm{ZHOU}}{ }^{1}, \mathrm{XING}_{\mathrm{ZHOU}}{ }^{1}, \mathrm{XI} \mathrm{ZHANG}^{2}$ and JING YANG ${ }^{2}$ \\ ${ }^{1}$ Department of Andrology, The First Hospital of Hunan University of Chinese Medicine, Changsha, Hunan 410007; \\ ${ }^{2}$ College of Pharmacy, Hunan University of Chinese Medicine, Changsha, Hunan 410208, P.R. China
}

Received May 28, 2018; Accepted March 12, 2019

DOI: $10.3892 /$ ijmm.2020.4569

\begin{abstract}
Stromal-epithelial interaction serves a pivotal role in normal prostate growth, as well as the onset of benign prostatic hyperplasia (BPH). The present study aimed to explore the role of cyclopamine in the proliferation and apoptosis of epithelial and stromal cells in rats with BPH by blocking the Hedgehog signaling pathway. Cyclopamine (an inhibitor of the Hedgehog signaling pathway) was administered in a rat model of $\mathrm{BPH}$, and the expression of $\mathrm{Ki67}$ (proliferation factor) was determined by immunohistochemistry. In addition, epithelial and stromal cells were separated and cultured in order to investigate the role of cyclopamine in the progression of BPH. The expression of Hedgehog signaling pathway- and apoptosis-related genes, including basic fibroblastic growth factor (b-FGF) and transforming growth factor $\beta$ (TGF- $\beta$ ), was evaluated using reverse transcription-quantitative polymerase chain reaction and western blot analysis. Cell proliferation, cell cycle and apoptosis were analyzed using an MTT assay and flow cytometry. We identified upregulated Ki67 expression and activated Hedgehog signaling pathway in rats with BPH. Cyclopamine inhibited the activation of the Hedgehog signaling pathway. In response to cyclopamine treatment, epithelial and stromal cell proliferation was inhibited; this was concomitant with decreased Ki67, TGF- $\beta$, and b-FGF expression. On the other hand, epithelial cell apoptosis was enhanced, which was associated with increased Bax and reduced Bcl-2 expression. Based on these findings, we proposed that cyclopamine may serve as a potential therapeutic agent in the treatment of BPH. Cyclopamine
\end{abstract}

Correspondence to: Dr Jing Yang, College of Pharmacy, Hunan University of Chinese Medicine, 300 Xueshi Road, Yuelu, Changsha, Hunan 410208, P.R. China

E-mail: yjyangjing2018@163.com

Key words: cyclopamine, Hedgehog signaling pathway, benign prostatic hyperplasia, apoptosis, proliferation, epithelial cell, stromal cell could inhibit epithelial and stromal cell proliferation, and induce epithelial cell apoptosis by suppressing the Hedgehog signaling pathway.

\section{Introduction}

Benign prostatic hyperplasia (BPH), an urologic and chronic disease, has been regarded as one of the most frequently occurring diseases among old-aged males, with proportions reaching $\leq 80 \%$ in males aged $>70$ years old $(1,2)$. Symptoms of BPH commonly include proliferation of smooth muscle and epithelial cells inside the prostatic transition area (3). $\mathrm{BPH}$ frequently begins as a simple micronodular hyperplasia that gradually develops into a macroscopic nodular growth; it can also cause urinary tract symptoms, such as increased urinary urgency and frequency, nocturia, and weak flow $(2,4)$. At present, there is an increased focus on treatments for BPH, such as transurethral resection of the prostate, pharmacotherapy and phytotherapy, particularly in western countries $(5,6)$.

Hedgehog refers to a group of proteins that were first detected in Drosophila, and serves significant roles in embryonic development (7). Additionally, the Hedgehog signaling pathway has been highlighted as crucial not only for maintaining the stem cell compartment, but also for cell proliferation and differentiation during embryonic tissue patterning (8). This signaling pathway, once activated, can also enhance oncogenesis due to its ability to promote tumor invasion and metastasis in a number of diseases, such as in prostate and pancreatic cancer, and gastric carcinoma (9). Gli1, Gli2 and Gli3 are important transcription factors in the Hedgehog signaling pathway, and when the Hedgehog signaling pathway is inactivated, the transcription of Gli1 is inhibited (10). In addition, $\beta$ transducing repeat containing 2 mediates the degradation of Gli2, and Gli3 is cleaved into small fragments in vivo, consequently, Gli proteins cannot enter the nucleus and exert their function as transcription factors (11). When Sonic Hedgehog (Shh) binds to cell membrane receptors and activates the Hedgehog signaling pathway, Gli proteins translocate into the nucleus, and mediates the transcription and expression of downstream 
target genes (12-14). A previous study revealed that blocking of Hedgehog signaling could suppress Shh-induced cell angiogenesis and migration (8). Cyclopamine is a powerful hedgehog signaling antagonist, and mainly targets the Smoothened (Smo) proteins (15).

The inhibitory effects of cyclopamine on the Hedgehog signaling pathway is achieved as follows: Cyclopamine binds directly to Smo, which affects its function and interferes with Shh signaling. Cyclopamine also inhibits the Hedgehog signaling pathway in a Ptch-independent manner and acts to suppress carcinogenesis. Additionally, it converts Smo into its active form (16). The mechanism by which cyclopamine specifically inhibits Shh activation is currently unclear. It was proposed that cyclopamine interferes with the reception of Hedgehog signaling in vertebrates; this process involves receptors with multiple transmembrane domains, namely, Ptch and Smo (17).

BPH is caused by a non-malignant proliferation of epithelial and stromal cells in the prostate gland areas (18). It has been reported that stromal-epithelial associations play central modulator roles in prostate growth and in homeostasis of the adult prostate (19). Previously, various studies have demonstrated close associations between cyclopamine and the Hedgehog signaling pathway, and this compound is commonly employed in the treatment of prostate cancer $(13,14)$. To further determine its functions and roles in regulating $\mathrm{BPH}$, the present study investigated the effects of cyclopamine on the proliferation and apoptosis of epithelial and stromal cells in rats with BPH by blocking the Hedgehog signaling pathway.

\section{Materials and methods}

Study subjects. A total of 15 normal male SD rats and 50 SD rats with BPH (6-8 weeks, weighing 400-450 g) were purchased from the Hunan SLAC Laboratory Animal Co., Ltd. (Changsha, China) and housed under a $12 \mathrm{~h}$ light/dark cycle at $22 \pm 2^{\circ} \mathrm{C}$ with relative humidity at $50 \pm 10 \%$. Following 1 week of acclimatization, rats were fasted overnight with free access to water prior to experiments. Cyclopamine $(0,10,20$ and $30 \mathrm{mg} / \mathrm{kg}$ ) was intraperitoneally injected into rats with BPH $(n=5)$, and BPH tissues was collected for western blot analysis of Smo protein. The remaining 45 rats were assigned into the normal group (normal rats, $n=15$ ), the BPH group $(\mathrm{BPH}$ rats, $\mathrm{n}=15)$ and the cyclopamine group (BPH rats, $\mathrm{n}=15)$. Rats in the cyclopamine group were intraperitoneally injected with $20 \mathrm{mg} / \mathrm{kg}$ cyclopamine. Rats in the normal and BPH groups were fed normally. After 1 week, rats were sacrificed via $\mathrm{CO}_{2}$ overdose; prostate tissues were obtained to determine the indexes described below. Wet weight was measured using an analytical balance, prostate volume was measured by the volumetric method (20), and prostate index (PI) was calculated using the formula: $\mathrm{PI}=$ wet weight of prostate/total body weight. All rats were fed in specific-pathogen-free grade chambers, which was compliant with the Laboratory Animal Requirements of Environment and Housing Facilities Guidelines (GB 14925-2010).

Hematoxylin and eosin $(H \& E)$ staining. Tissues were sectioned $\left(5-\mu \mathrm{m}\right.$ thick), laid out at $45^{\circ} \mathrm{C}$, selected and dried at $60^{\circ} \mathrm{C}$ for $1 \mathrm{~h}$. They were then deparaffinized with xylene and stained with the H\&E solution (Beijing Solarbio Science $\&$ Technology Co., Ltd. Beijing, China). Then, tissue sections were dehydrated with an ethanol gradient (50, 70, 80 and 95\%), cleared with xylene, mounted using neutral gum, and observed under a Zeiss fluorescence microscope (magnification x400; Axio Observer A1/D1/Z1, Zeiss AG to analyze histopathological changes in prostate tissues.

Terminal deoxynucleotidyl transferase-mediated dUTP nick-end labeling (TUNEL) staining. Triton X-100 (0.1\%) was added to tissue sections, which were then placed on ice for $4 \mathrm{~min}$ and washed three times with PBS (2 min each time). TUNEL reaction solution (50 $\mu \mathrm{l}$, ZK-8005, Beijing Zhongshan Jinqiao Biotechnology Co., Ltd.) was added for $1 \mathrm{~h}$ at $37^{\circ} \mathrm{C}$; tissues were then washed three times with PBS. Diaminobenzidine $/ \mathrm{H}_{2} \mathrm{O}_{2}$ solution (cat. no. 2014, Invitrogen; Thermo Fisher Scientific, Inc.) was then added for $5 \mathrm{~min}$ at room temperature, after which it was terminated by washing the sections with PBS. Hematoxylin was applied for re-staining at $37^{\circ} \mathrm{C}$ for $10 \mathrm{sec}$, and sections were dehydrated, cleared, sealed with anti-fluorescence quenching sealing solution and observed under a fluorescence microscope (magnification x400; BX43; Olympus Optical Co., Ltd.) with five high power fields randomly selected to count the number of TUNEL positive cells.

Immunohistochemistry. Tissues were fixed using formaldehyde, paraffin-embedded, and sectioned into $4 \mu \mathrm{m}$ slices. They were then dried in a $60^{\circ} \mathrm{C}$ incubator for $1 \mathrm{~h}$, deparaffinized by xylene (Mingtou Industry and Trade Co., Ltd., Shanghai, China), dehydrated an ethanol gradient (50, 70, 80 and 95\%), incubated with $3 \% \mathrm{H}_{2} \mathrm{O}_{2}$ for $10 \mathrm{~min}$, and finally washed with PBS. Antigen retrieval was performed under high pressure for $90 \mathrm{sec}$, after which samples were cooled down to room temperature. Non-specific binding was blocked with 5\% bovine serum albumin (BSA; Shanghai Sangon Biological Engineering Technology \& Services Co., Ltd.) blocking buffer at $37^{\circ} \mathrm{C}$ for $30 \mathrm{~min}$. Tissue sections were then incubated with the primary antibody (1:200, Ki67 monoclonal antibody, Biogot Technology, Inc., Nanjing, China) at $4^{\circ} \mathrm{C}$ overnight. Goat anti-mouse IgG secondary antibody labeled by biotin (1:1,000, ab6759, Abcam Inc., Cambridge, MA, USA) was added at $37^{\circ} \mathrm{C}$ for $30 \mathrm{~min}$. Subsequently, streptavidin solution (Zhongshan Goldenbridge Biotechnology, Co. Ltd., Beijing, China) was added at $37^{\circ} \mathrm{C}$ for $30 \mathrm{~min}$. This was followed by addition of 3,3'-diaminobenzidine (Bioss Biotechnology Co., Ltd., Beijing, China) for $5 \mathrm{~min}$ at room temperature. Tissues were washed with water for $5 \mathrm{~min}$, and were immersed in the hematoxylin solution (Yinggong Reagent Co., Ltd., Shanghai, China) for $5 \mathrm{~min}$ at $37^{\circ} \mathrm{C}$. Lastly, tissues were washed with running water. $\mathrm{PBS}$ was used in place of the primary antibody in the negative control group. Tissue sections with positive expression were included in the positive control group. Tissue sections were observed and imaged under an optical microscope (XSP-36, Boshida Optical Instrument Co., Shenzhen, China). A total of five high power fields (magnification, x200) were randomly selected, and 100 prostate cells in each field were analyzed. If the percentage of cells with positive expression was $<10, \geq 10$ but $<50 \%$, or $\geq 50 \%$, the staining result is negative, positive, or strongly positive, respectively (15). 
Cell treatment. A region of the anterior lobe on the right side and ventral lobe of the prostate were collected, washed twice with the D-Hanks solution, and cut into pieces. Any visible macrovascular tissue was removed, and the lobes were digested with $2 \%$ trypsin at room temperature for $30 \mathrm{~min}$. Following a $5-\mathrm{min}$ centrifugation at $1,789 \times \mathrm{g}$ at $25^{\circ} \mathrm{C}$, tissues were digested with $0.06 \%$ collagenase type II at room temperature for $15 \mathrm{~min}$, and were then filtered. The filtrate was mixed evenly with culture suspension of epithelial cells, which was then inoculated in a culture flask embedded with fibronectin (Shanghai Sangon Biological Engineering Technology \& Services Co., Ltd.). Cells were cultured with $10 \%$ fetal bovine serum (FCS500, Excell Bio Company, Shanghai, China) at $5 \% \mathrm{CO}_{2}$ and $37^{\circ} \mathrm{C}$. A mixture composed of insulin-transferrin-selenium (with a volume ratio of $1: 100), 0.5 \mu \mathrm{g} / 1 \beta$-endothelial cell growth factor and $100 \times 10^{3} \mathrm{U} / 1$ penicillin-streptomycin double-antibody (B540732; Shanghai Sangon Biological Engineering Technology \& Services Co., Ltd.) was added.

MTT assay. Epithelial and stromal cells $\left(2.5 \times 10^{5}\right.$ cells $\left./ \mathrm{ml}\right)$ were seeded into a 96 -well plate. Cells were maintained in an incubator at $5 \% \mathrm{CO}_{2}$ and $37^{\circ} \mathrm{C}$. The plate was removed on days 1, 2, 3, 4 and 5 for the MTT assay. Briefly, $10 \mu \mathrm{l}$ MTT solution (5 g/l) (GD-Y1317, Guduo Biotechnology Company, Shanghai, China) was added into each well. Cells were then further incubated at $37^{\circ} \mathrm{C}$ for $24 \mathrm{~h}$. This was followed by the addition of $100 \mu 1$ dimethyl sulfoxide (D2650, Sigma-Aldrich; Merck KGaA, Darmstadt, Germany). The plate was then slightly shaken and mixed evenly for $10 \mathrm{~min}$. An automatic enzyme-labelled reading meter (BS-1101, Detielab Co., Ltd., Nanjing, China) was used to measure the optical density value at $490 \mathrm{~nm}$.

Flow cytometry. Cells were collected by $0.25 \%$ trypsin at $37^{\circ} \mathrm{C}$ for $30 \mathrm{~min}$, washed with PBS, and re-centrifuged at $1,145 \mathrm{x} \mathrm{g}$ for $5 \mathrm{~min}$ at room temperature. Cell precipitates were fixed using pre-cooled $70 \%$ ethanol at $4^{\circ} \mathrm{C}$ overnight, and washed twice with PBS. Cell suspension (100 $\mu 1$, total number of cells no less than $10^{6}$ cells $/ \mathrm{ml}$ ) was obtained, to which $1 \mathrm{ml}$ of $50 \mathrm{mg} / \mathrm{l}$ propidium iodide (containing RNAase, Sigma-Aldrich; Merck $\mathrm{KGaA}$ ) was added. Staining was conducted for $30 \mathrm{~min}$ in the dark. A nylon net with 100 pores was used for filtration; flow cytometry was performed with an excitation wavelength of $488 \mathrm{~nm}$ for cell cycle analysis (ModFit LT; version 4.1; Verity Software House, Inc.).

Annexin V-fluorescein isothiocyanate (FITC)/propidium iodide double staining was used to examine cell apoptosis; cells were treated aforementioned for cell cycle analysis. Cells were then incubated for $48 \mathrm{~h}$ at $37^{\circ} \mathrm{C}$ with $5 \% \mathrm{CO}_{2}$. Subsequently, cells were collected, washed twice with PBS, centrifuged at $1,145 \mathrm{x} \mathrm{g}$ for $5 \mathrm{~min}$ at room temperature, and resuspended in $200 \mu \mathrm{l}$ binding buff er. As per the instructions of the Annexin-V-FITC cell apoptosis detection kit (K201-100, BioVision, Mountain View, CA, USA), Annexin V-FITC, PI and HEPES were used to make up the Annexin V-FITC/propidium iodide cocktail in a 1:2:50 ratio. Cells were then incubated in the dark at room temperature for $20 \mathrm{~min}$. Flow cytometry was used to detect cell apoptosis at an excitation wavelength of $488 \mathrm{~nm}$. The experiment was repeated three times.
Reverse transcription quantitative polymerase chain reaction $(R T-q P C R)$. Total RNA in prostate cells of all rats were extracted with TRIzol (Invitrogen; Thermo Fisher Scientific, Inc.). RT-qPCR was carried out according to the instructions provided by the TaqMan MicroRNA Assays Reverse Transcription kit (cat. no. 4427975, Applied Biosystems Inc.; Thermo Fisher Scientific, Inc.) using an ABI7500 quantitative PCR instrument (7500, ABI Company, Oyster Bay, N.Y., USA). The qPCR reaction conditions were as follows: Pre-denaturation $\left(95^{\circ} \mathrm{C}\right)$ for $5 \mathrm{~min}$, denaturation $\left(94^{\circ} \mathrm{C}\right)$ for $10 \mathrm{sec}$, annealing for $30 \mathrm{sec}$ at $30^{\circ} \mathrm{C}$, and DNA strand extension for $15 \mathrm{sec}$ at $72^{\circ} \mathrm{C} ; 40$ cycles were performed in total. GAPDH was used as the internal reference gene, and relative mRNA expression was determined by the $2^{-\Delta \Delta \mathrm{Cq}}$ method (21), where $\Delta \mathrm{Ct}=\mathrm{Ct}_{\text {targeted gene }}-\mathrm{Ct}_{\mathrm{GAPDH}}$. The experiment was repeated three times. Primer sequences of RT-qPCR are listed in Table I.

Western blot analysis. Protein was detected using the bicinchoninic acid kit (cat. no. 20201ES76; Yeason Biotechnology Co. Ltd.); samples were diluted in deionized water to achieve a loading quantity of $30 \mu \mathrm{g}$ protein per lane. Proteins were separated via SDS-PAGE (12\% gel) transferred onto a nitrocellulose membrane, which was sealed using 5\% skim milk powder at $4^{\circ} \mathrm{C}$ and kept overnight. Diluted primary anti-rabbit polyclonal antibodies were added to the cells, and included Shh (1:1,000, ab53281, Abcam), Gli1 (1:1,500, ab151796, Abcam), Ptch1 (1:1,500, ab53715, Abcam), basic fibroblastic growth factor (b-FGF; 1:200, ab99979, Abcam), transforming growth factor $\beta$ (TGF- $\beta$; ab31013, Abcam), B-cell lymphoma-2 (Bcl-2)-associated X protein (Bax; 1:2,000, ab32503, Abcam), Bcl-2 (1:500, ab692, Abcam), and GAPDH (1:2,500, ab9485, Abcam). The rabbit anti-human monoclonal secondary antibody (1:200, bs-0361R-HRP, BIOSS Company, Beijing, China) was used then added. Subsequently, protein bands were visualized using electrochemical luminescence (ECL808-25, Biomiga, Inc., San Diego, CA, USA) and analyzed by Image J software (version 2.1.4.7; National Institutes of Health Inc.).

Statistical analysis. All data were analyzed with the SPSS 21.0 software (IBM Corp., Armonk, NY, USA). Data were presented as the mean \pm standard deviation. Comparisons among multiple groups were determined by one-way analysis of variance. Pairwise comparison of mean values was analyzed by the Least Significant Difference method. $\mathrm{P}<0.05$ was considered to indicate a statistically significant difference.

\section{Results}

Cyclopamine decreases wet weight, volume, and PI of prostate in rats with $B P H$. In our study, we administered 0, 10, 20 and $30 \mathrm{mg} / \mathrm{kg}$ cyclopamine to rats with $\mathrm{BPH}$ rats $(\mathrm{n}=5)$, and $\mathrm{BPH}$ tissues were collected for determination of wet weight, volume, and PI of prostate in rats with BPH. The wet weight, volume and PI of prostate tissues in rats among the three groups were observed following establishment of the BPH model (Fig. 1). As compared with those in the normal group, the wet weight, volume and PI of the prostate were significantly increased in the $\mathrm{BPH}$ and cyclopamine groups $(\mathrm{P}<0.05)$. As compared with the BPH group, these parameters in the cyclopamine group were significantly decreased $(\mathrm{P}<0.05)$. 
Table I.Primer sequences for reverse transcription-quantitative polymerase chain reaction.

\begin{tabular}{|c|c|}
\hline Gene & Premier sequence (5'-3') \\
\hline \multirow[t]{2}{*}{ Shh } & Forward: ACCGAGGGCTGGGACGAAGA \\
\hline & Reverse: ATTTGGCCGCCACCGAGTT \\
\hline \multirow[t]{2}{*}{ Ptch1 } & Forward: TTTGGACTGCTTCTGGGAAGGG \\
\hline & Reverse: TTTTTGTTGGGGGCTGTGGC \\
\hline \multirow[t]{2}{*}{ Gli1 } & Forward: GAAGGTGAAGGTCGGAGT \\
\hline & Reverse: GTCCAGGCTGGCATCCGACA \\
\hline \multirow[t]{2}{*}{ b-FGF } & Forward: GAGGAGTTGTGTCTATCAAAG \\
\hline & Reverse: GTTCGTTTCAGTGCCACATACC \\
\hline \multirow[t]{2}{*}{ TGF- $\beta$} & Forward: CAAGAGGCTGTGTTGVTGTGAATC \\
\hline & Reverse: GTTGGTTTGAGAAAATCCATCGG \\
\hline \multirow[t]{2}{*}{ Bax } & Forward: GACCAGGGTGGCTGGGAAGG \\
\hline & Reverse: GATGGTGAGCGAGGCGGTGA \\
\hline \multirow[t]{2}{*}{$\mathrm{Bcl}-2$} & Forward: CCGGCATCTGCACACCTGG \\
\hline & Reverse: CACAACTTTGTTTCATGGTCCATCC \\
\hline \multirow[t]{2}{*}{ GAPDH } & Forward: AACGGATTTGGTCGTATTGGG \\
\hline & Reverse: TCGCTCCTGGAAGATGGTGAT \\
\hline
\end{tabular}

Shh, sonic hedgehog; Ptch1, Patched-1; Gli1, glioma-associated oncogene homolog 1 ; b-FGF, basic fibroblastic growth factor, TGF- $\beta$, transforming growth factor $\beta$; GAPDH, glyceraldehyde-phosphate dehydrogenase.

Histopathological alterations in the prostate tissues after BPH model establishment and in response to cyclopamine treatment. H\&E staining was conducted to observe the histopathological changes in rat prostate tissues. As presented in Fig. 2, prostatic epithelial cells in the normal group showed regular alignment as a columnar monolayer. Glands were of similar size, and were regularly arranged; the prostatic cavity was not expanded. In the BPH group, prostatic epithelia were observed to exhibit papillary hyperplasia and protrusion into the prostatic cavity in a zigzag fashion. The mesenchyme and surrounding vessels were expanded, with accompanying hyperemia and edema. Few glands were expanded, and the prostatic cavity was also enlarged. Regarding the cyclopamine group, prostatic epithelial cells were arranged in a columnar monolayer. The mesenchyme and the surrounding vessels were also expanded, along with hyperemia and slight edema. Few glands exhibited expanded cavities with hyperplasia.

Cyclopamine increases apoptotic body formation in BPH rats. A TUNEL assay was performed to investigate the effects of cyclopamine on prostate tissue cell apoptosis in BPH rats (Fig. 3). Compared with that of the normal group, apoptotic body formation was significantly reduced in the BPH and cyclopamine groups $(\mathrm{P}<0.05)$. Additionally, compared with that of the BPH group, apoptotic body formation was significantly increased in the cyclopamine group $(\mathrm{P}<0.05)$.

As TUNEL staining was enhanced and apoptotic body formation was increased in the cyclopamine group, these parameters may serve as indicators in evaluating BPH. Our

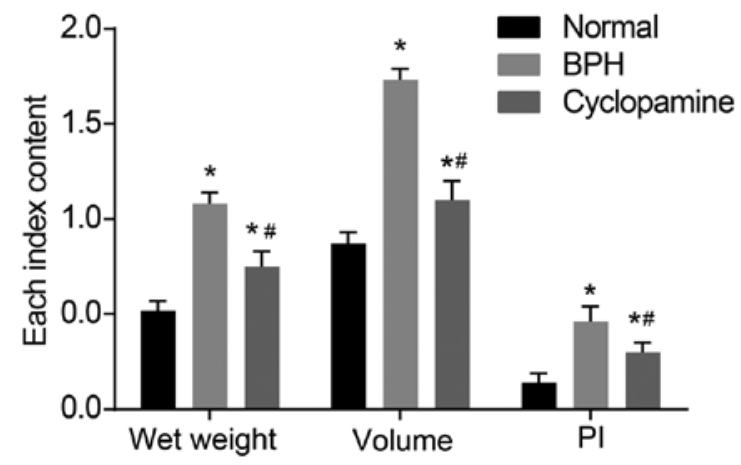

Figure 1. Wet weight, volume, and PI of prostate were reduced in BPH rats in response to cyclopamine treatment. BPH, benign prostatic hyperplasia; PI, prostate index. ${ }^{*} \mathrm{P}<0.05$ vs. normal group. ${ }^{~} \mathrm{P}<0.05$ vs. $\mathrm{BPH}$ group. $\mathrm{PI}$, prostate index; $\mathrm{BPH}$, benign prostatic hyperplasia.

results suggested that cyclopamine could upregulate apoptotic body formation in BPH rats, as presented in Fig. 3B.

Cyclopamine reduces rate of Ki67 positive expression in BPH rats. The effects of cyclopamine on Ki67 expression in BPH rats was assessed by immunohistochemistry (Fig. 4A). As compared with that of the normal group, the positive Ki67 expression in the BPH and cyclopamine groups was significantly increased $(\mathrm{P}<0.05)$, which suggested $\mathrm{Ki} 67$ as an indicator for evaluating BPH. Compared with the BPH group, positive Ki67 expression was significantly decreased in the cyclopamine group $(\mathrm{P}<0.05)$. The results further suggested that cyclopamine could inhibit Ki67 protein expression (Fig. 4B). Collectively, our results suggested that cyclopamine inhibited BPH in rats by suppressing the expression of the cell proliferation marker Ki67 in BPH tissues.

Cyclopamine hinders epithelial and stromal cell proliferation in BPH rats. An MTT assay was performed to determine the effects of cyclopamine on the proliferation of stromal (Fig. 5A) and epithelial cells (Fig. 5B) in BPH rats. As compared with the control group, cell proliferation in the BPH and cyclopamine groups was significantly increased $(\mathrm{P}<0.05)$. Compared with the BPH group, cell proliferation in the BPH group was significantly decreased $(\mathrm{P}<0.05)$. These findings suggested that cyclopamine could inhibit proliferation of epithelial and stromal cells in the prostate. The numbers of epithelial and stromal cells in prostate tissues were recorded via the cell counting method (Fig. 5C and D). Changes in the numbers of epithelial and stromal cells were comparable between the MTT assay and the cell counting method. Hence, cyclopamine contributed to repressed epithelial and stromal cell proliferation in BPH rats.

Cyclopamine inhibits epithelial cell cycle progression and promotes epithelial cell apoptosis in BPH rats. Propidium iodide staining was adopted to detect epithelial cell cycle distribution (Fig. 6A-D). As compared with the normal group, the proportion of cells arrested at the G0/G1 phase in the BPH and cyclopamine groups was significantly reduced, while the proportion of cells at arrested the $\mathrm{S}$ phase was increased $(\mathrm{P}<0.05)$. Compared with the BPH group, the proportion of cells arrested at the G0/G1 phase in the cyclopamine group was significantly increased, while that of cells arrested at the $\mathrm{S}$ phase were reduced $(\mathrm{P}<0.05)$. Results 

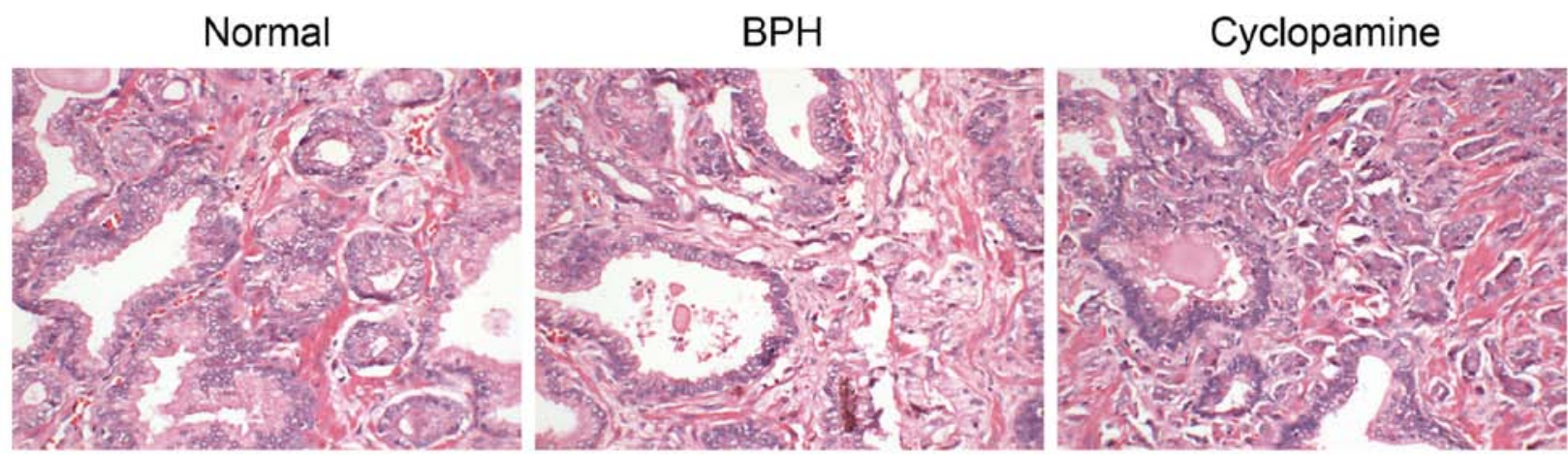

Figure 2. H\&E staining (magnification, $\mathrm{x} 400$ ) of prostate tissues in BPH rats in response to cyclopamine treatment. In the normal group, glands were of the same size, and were regularly arranged; the prostatic cavity was not expanded. In the BPH group, the number of glands was increased and densely aligned; some glands were expanded, and the prostatic cavity was also enlarged. In the cyclopamine group, only a few of the glands exhibited cavity expansion with hyperplasia. BPH, benign prostatic hyperplasia.

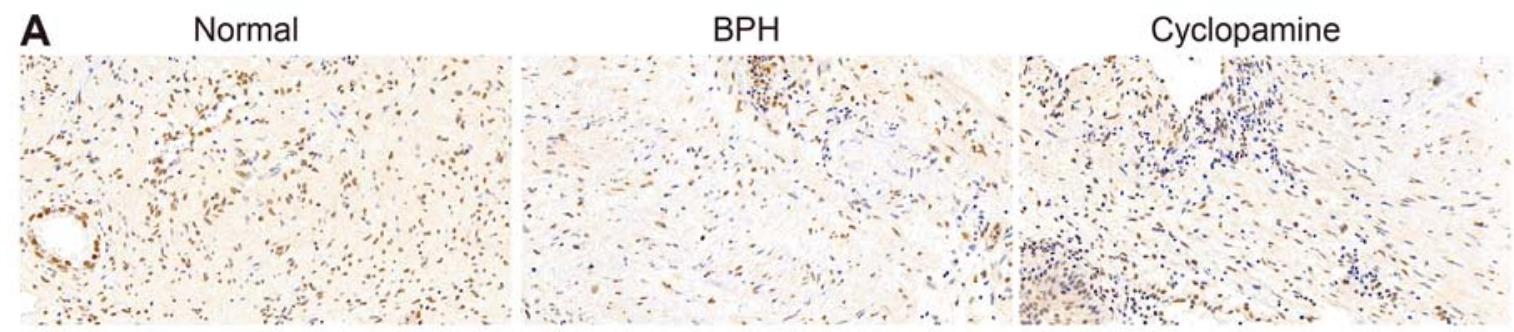

B

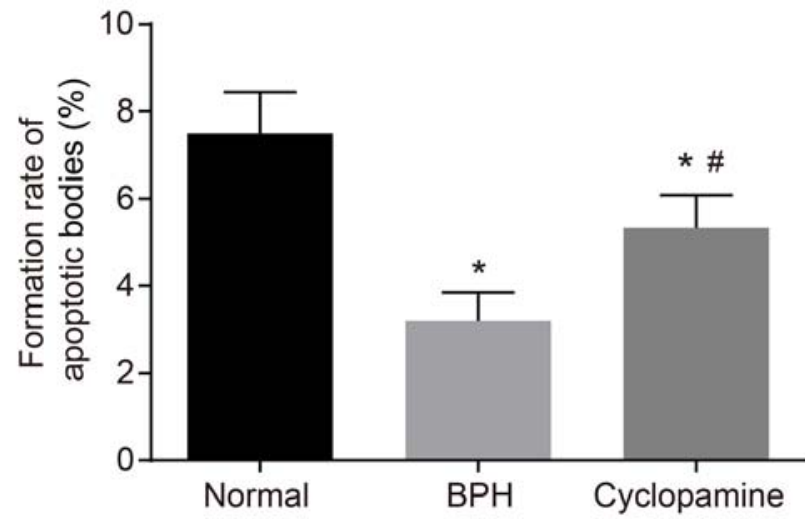

Figure 3. TUNEL assay indicates that cyclopamine promotes apoptotic body formation in BPH rats (A) TUNEL staining (magnification, $\mathrm{x} 400$ ) of apoptotic body formation in the normal, BPH and cyclopamine groups. (B) Formation rate of apoptotic bodies was increased in BPH rats upon cyclopamine treatment; ${ }^{*} \mathrm{P}<0.05$ vs. normal group. ${ }^{\#} \mathrm{P}<0.05$ vs. $\mathrm{BPH}$ group. $\mathrm{BPH}$, benign prostatic hyperplasia; TUNEL, terminal deoxynucleotidyl transferase-mediated dUTP nick-end labeling.

indicated that cyclopamine could suppress cell proliferation and arrest cells at the G0/G1 phase.

Annexin V-FITC/propidium iodide double staining was adopted to assess epithelial cell apoptosis. The number of apoptotic cells in the BPH and cyclopamine groups were significantly reduced compared with the control group $(\mathrm{P}<0.05)$. Conversely, the number of apoptotic cells in the cyclopamine group was significantly increased $(\mathrm{P}<0.05)$ than that of the BPH group. These results suggested that cyclopamine could induce the apoptosis of epithelial cells in $\mathrm{BPH}$ rats.

Cyclopamine decreases the expression of Shh, Ptchl, Glil, $b-F G F, T G F-\beta$ and Bcl-2, but increases that of Bax in BPH rats. Finally, RT-qPCR (Fig. 7) and western blot analysis (Fig. 8) were used to measure mRNA and protein levels of Hedgehog signaling pathway- and apoptosis-associated genes, as well as b-FGF and TGF- $\beta$. Compared with the normal group, the mRNA and protein levels of Shh, Ptch1, Gli1, b-FGF, TGF- $\beta$, and Bcl- 2 were significantly increased in the BPH and cyclopamine groups; conversely, Bax mRNA and protein levels were significantly decreased $(\mathrm{P}<0.05)$. In addition, as compared with those of the BPH group, the protein levels of Shh, Ptch1, Gli1, b-FGF, TGF- $\beta$ and Bcl-2 were greatly reduced in the cyclopamine group, while Bax mRNA and protein levels were greatly increased $(\mathrm{P}<0.05)$. These results indicated that cyclopamine blocks the Hedgehog signaling pathway to inhibit cell proliferation and enhances apoptosis in $\mathrm{BPH}$ rats.

\section{Discussion}

In recent years, BPH has become a disease that affects an increasing number of males $>50$ years old across the world due 


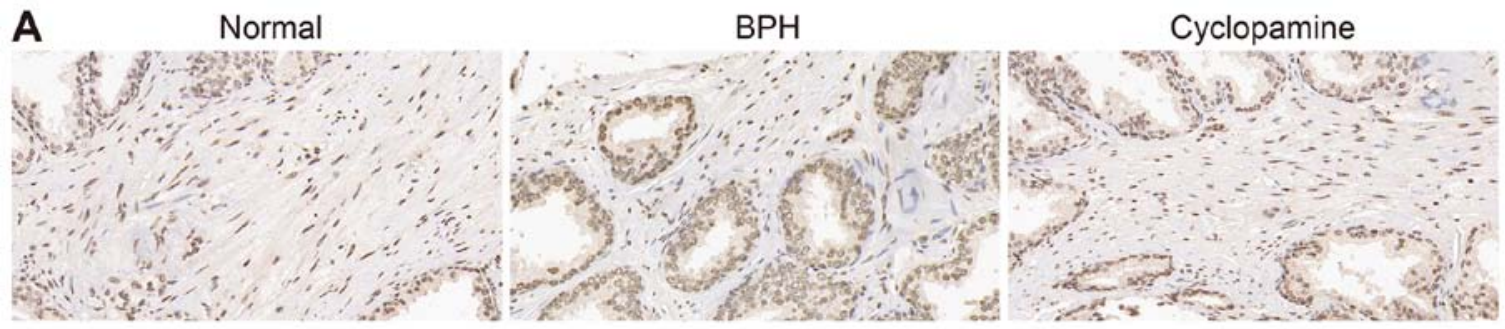

B

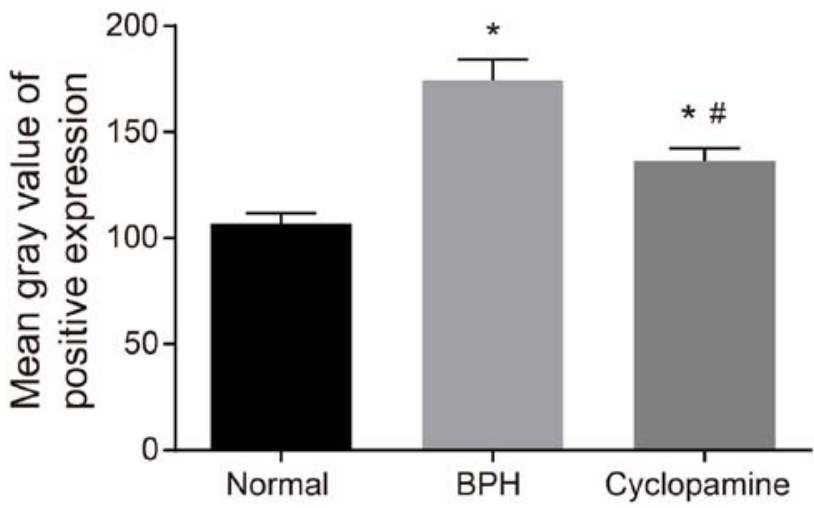

Figure 4. Ki67 expression downregulated in the prostatic of BPH rat administered cyclopamine. (A) Immunohistochemical staining (magnification, $\mathrm{x} 400$ ) for Ki67 expression in the normal, BPH and cyclopamine groups. (B) Quantitative analysis of positive Ki67 expression. ${ }^{*} \mathrm{P}<0.05$ vs. normal group. ${ }^{\#} \mathrm{P}<0.05$ vs. $\mathrm{BPH}$ group. $\mathrm{BPH}$, benign prostatic hyperplasia.

A

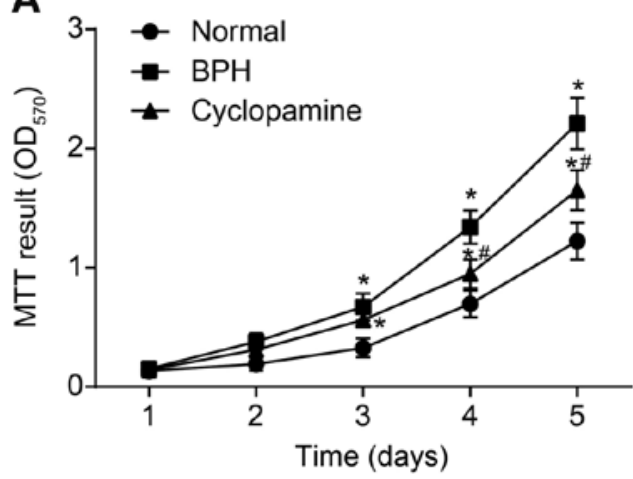

C

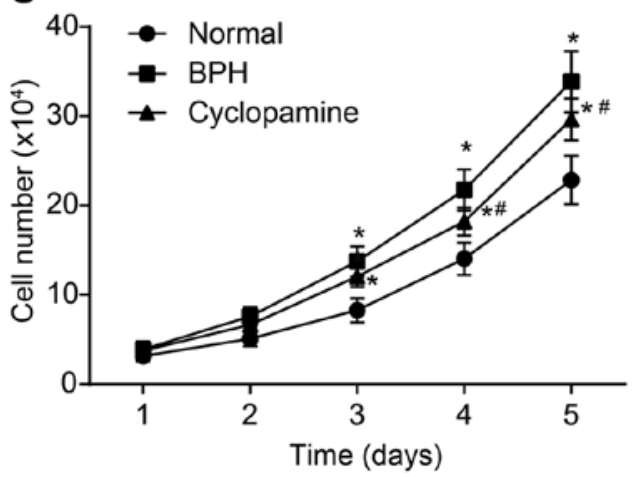

B

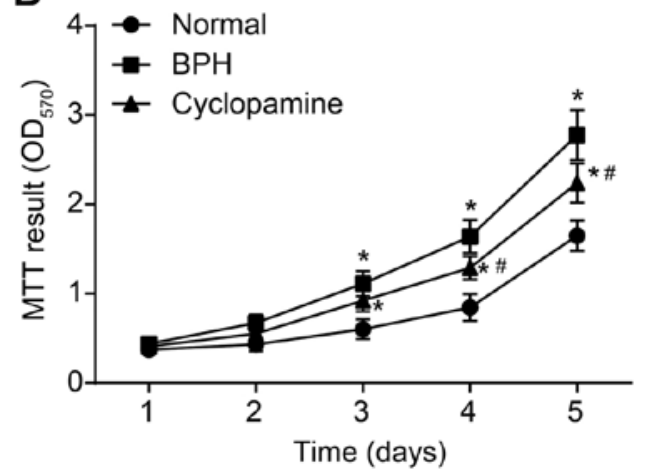

D

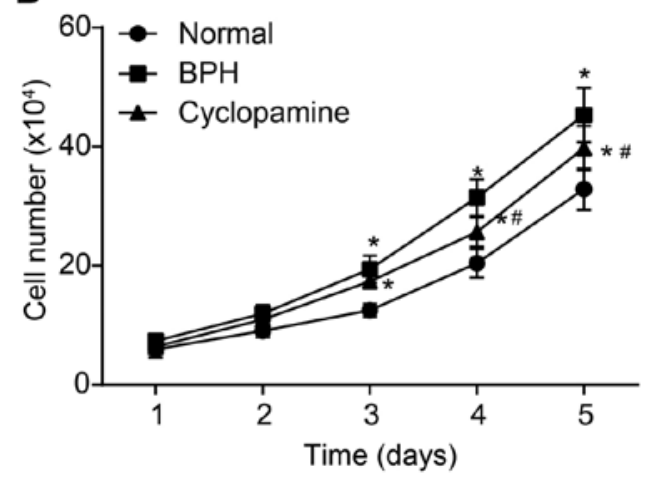

Figure 5. MTT assay and cell counting methods reveal that cyclopamine inhibits stromal and epithelial cell proliferation. Proliferation potential of (A) stromal cells and (B) epithelial cells in each group as detected by an MTT assay. Changes in the number of (C) stromal cells and (D) epithelial cells in each group; ${ }^{*} \mathrm{P}<0.05$ vs. normal group. ${ }^{\text {}} \mathrm{P}<0.05$ vs. $\mathrm{BPH}$ group. $\mathrm{BPH}$, benign prostatic hyperplasia.

to its poorly understood pathogenesis (4). Studies have reported that the Hedgehog signaling pathway is activated in prostate cancers $(16,22)$. As an inhibitor of the Hedgehog signaling pathway, cyclopamine serves a crucial role in suppressing prostate cancer and improving survival (13); however, the underlying mechanism of action in BPH remains uncertain. Thus, the present study aimed to investigate the effects of cyclopamine on the proliferation and apoptosis of epithelial 

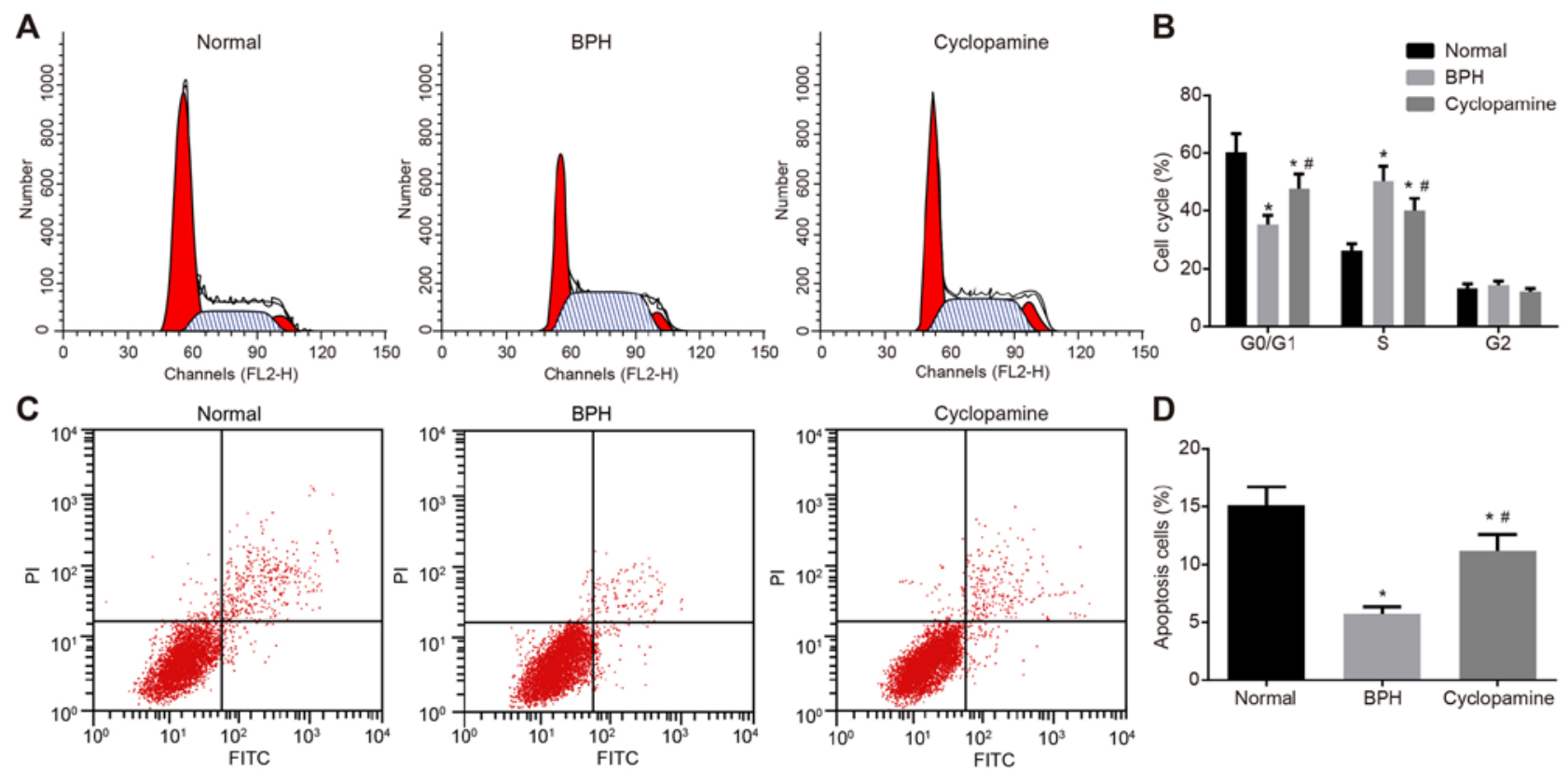

Figure 6. Flow cytometry indicates that cyclopamine suppresses epithelial cell cycle progression and promotes their apoptosis in BPH rats. (A) PI single staining indicated epithelial cell cycle distribution in the normal, BPH and cyclopamine groups. (B) Quantitative analysis of epithelial cell cycle distribution. (C) Annexin V-FITC/PI double staining. (D) Quantitative analysis of epithelial cell apoptosis. " $\mathrm{P}<0.05$ vs. normal group. ${ }^{\text {}} \mathrm{P}<0.05$ vs. BPH group. BPH, benign prostatic hyperplasia; FITC, fluorescein isothiocyanate; PI, propidium iodide.

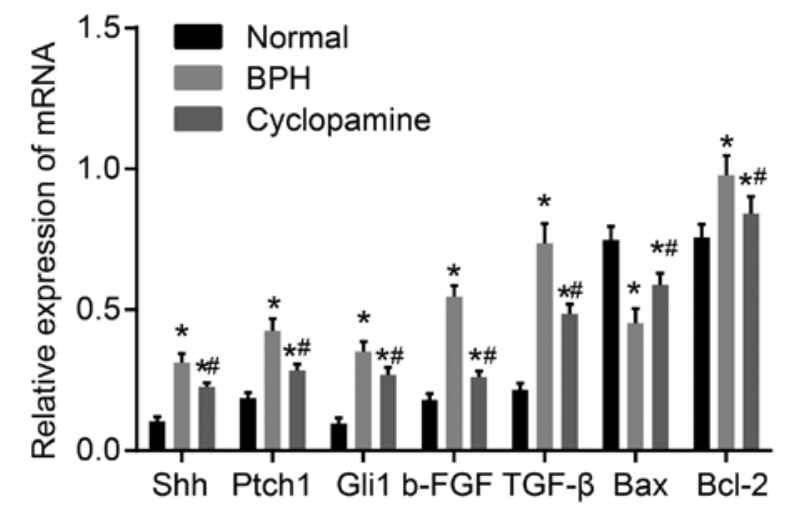

Figure 7. Effect of cyclopamine on mRNA expression of Shh,Ptch1, Gli1, b-FGF, TGF- $\beta$, and $\mathrm{Bcl}-2$ in the normal, BPH and cyclopamine groups. ${ }^{*} \mathrm{P}<0.05$ vs. normal group. ${ }^{\#} \mathrm{P}<0.05$ vs. BPH group. Shh, sonic hedgehog; Ptch1, Patched-1; Gli1, glioma-associated oncogene homolog 1; Bcl-2, B-cell lymphoma 2; Bax, Bcl-2-associated X protein; b-FGF, basic fibroblastic growth factor, TGF- $\beta$, transforming growth factor $\beta$; BPH, benign prostatic hyperplasia.

and stromal cells in BPH rats by blocking the Hedgehog signaling pathway.

Initially, our results demonstrated that cyclopamine could decrease the wet weight, the volume and PI of prostate in BPH rats. In addition, the formation of nodular overgrowth in the epithelium and fibromuscular tissues inside the transition zone and the periurethral areas have also been observed (23). Glandular hyperplasia and interstitial hyperplasia can contribute to enlarged prostates (24). BPH rats exhibited higher wet weight and volume of prostate glands in the present study. Based on the evaluation of these variables, we hypothesized that cyclopamine may suppress BPH.

Immunohistochemistry analysis showed that cyclopamine could reduce the rate of positive Ki67 expression in $\mathrm{BPH}$ rats. Ki67 antigen has been reported as an effective tool in diagnosing and evaluating proliferative activity in normal prostate tissues, prostatic intraepithelial neoplasia and prostatic tumors $(25,26)$. Ki67 is associated with the proliferative phase of cell cycle, and its overexpression can lead to a robust increase in the number of prostatic cells (27). Therefore, we evaluated $\mathrm{Ki} 67$ expression in proliferating prostate cells in all three groups. Our study revealed that cyclopamine could suppress cell proliferation and promote cell apoptosis in prostate tissues in BPH rats. Despite its uncertain pathogenesis, the progression of BPH is highly associated with decreased cell apoptosis, which leads to an elevated number of stromal and epithelial cells (28). The Hedgehog signaling pathway has been reported to be a positive regulator and a proliferative stimulus during prostate cell growth (29). Inhibition of this signaling cascade by cyclopamine can lead to increased cell apoptosis $(30,31)$, which is in consistent with our findings. $\mathrm{BPH}$ is characterized by the hyper-proliferation of epithelial and stromal prostatic cells, which results in complex cellular alterations (32). The development of BPH is concomitant with a decline in stromal and epithelial cell apoptosis (28). As cyclopamine can inhibit the Hedgehog signaling pathway, which is a crucial participator in prostatic cell progression, it may ultimately inhibit the apoptosis of epithelial cells (15).

Finally, our results indicated that expression of Shh, Ptch1, Gli1, b-FGF, TGF- $\beta$ and Bcl-2 increased significantly, while Bax expression reduced substantially in rat models of BPH. This was also associated with activated Hedgehog signaling, increased proliferation and reduced cell apoptosis. In response to cyclopamine administration, the Hedgehog signaling pathway was inhibited, cell proliferation was suppressed, and cell apoptosis was enhanced. Shh/Ptch1/Gli1 are three essential members in the Hedgehog signaling pathway that can exert notable effects on the progression of BPH (33). As 
A

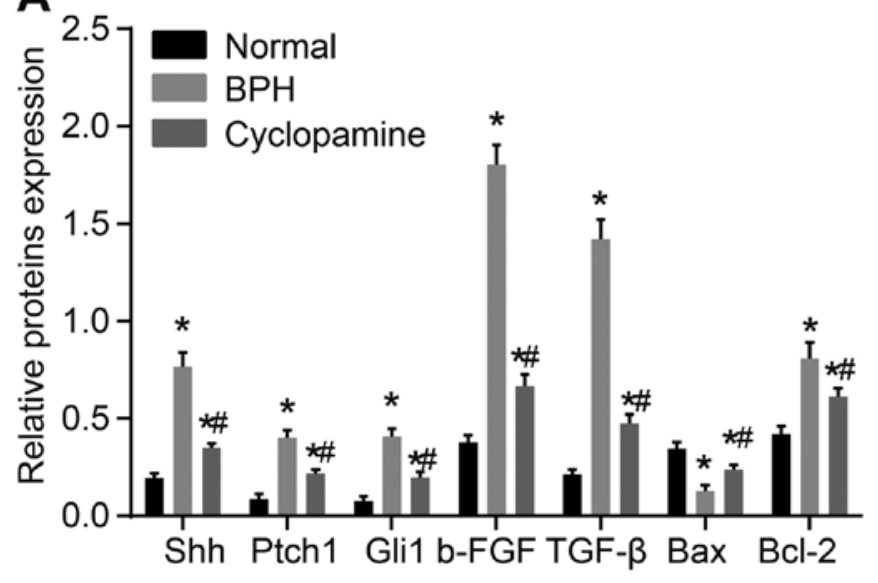

B

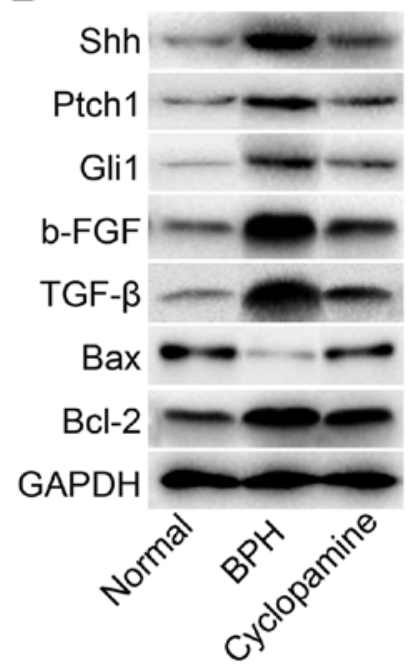

Figure 8 . Western blot showing protein levels of Shh, Ptch1, Gli1, b-FGF, TGF- $\beta$ and Bcl-2 in BPH rats. (A) Protein bands of Shh, Ptch1, Gli1, b-FGF, TGF- $\beta$, Bax, and Bcl-2. (B) Quantitative analysis of the relative protein expression levels of Shh, Ptch1, Gli1, b-FGF, TGF- $\beta$, Bax and Bcl-2. ${ }^{*}<0.05$ vs. normal group. ${ }^{\#} \mathrm{P}<0.05$ vs. BPH group. Shh, sonic hedgehog; Ptch1, Patched-1; Gli1, glioma-associated oncogene homolog 1; Bcl-2, B-cell lymphoma 2; Bax, Bcl-2-associated $\mathrm{X}$ protein; b-FGF, basic fibroblastic growth factor, TGF- $\beta$, transforming growth factor $\beta$; BPH, benign prostatic hyperplasia.

a gene encoding angiogenic cytokine, b-FGF was reported to induce epithelial cell proliferation, which can further promote BPH (34). A previous study has confirmed the role of TGF- $\beta$ in aggravating BPH (23). Bcl-2 and Bax belong to the Bcl-2 family of proteins, with the former serving as an anti-apoptotic member, while the latter acts as a pro-apoptotic molecule $(28,35)$. When Bcl-2 expression was reduced and Bax expression was increased, BPH progression was inhibited (36).

Taken together, the present study is the first to explore the functional role of cyclopamine in BPH to the best of our knowledge. Prior to this, clinical research studies have shown that $\alpha 1$ antagonists, $5 \alpha$ reductase inhibitors, and a combination of these two molecules can inhibit BPH (37). In addition, silencing of upregulated gene 11 can also inhibit the proliferation and epithelial-mesenchymal transition of BPH cells (38). In addition, Wang et al (39) showed that metformin could suppress BPH epithelial cell proliferation by inhibiting the secretion of insulin-like growth factor (IGF)-1 receptor and IGF-1 in stromal cells.

This study demonstrated that cyclopamine reduced the proliferation of epithelial and stromal cells, and promoted epithelial cell apoptosis by blocking the Hedgehog signaling pathway in BPH rats. Future studies are still required to investigate the mechanism by which inhibition of Hedgehog signaling by cyclopamine can restrict the progression of $\mathrm{BPH}$. This may also provide novel insights into potential treatments BPH with cyclopamine.

\section{Acknowledgements}

Not applicable.

\section{Funding}

The present study was supported by the Clinical Medical Technological Innovation Guidance Project of Technological Innovation Guidance Plan in Hunan Province (grant
no.2017SK50305), the Scientific Research Project of Traditional Chinese Medicine in Hunan Province (grant no. 201832), the General Program of National Natural Science Foundation of China (grant no. 81673984), and the Construction Project of He Juqiao's National Traditional Chinese Medicine Expert Inheritance Studio. The authors thank the reviewers for their helpful comments.

\section{Availability of data and materials}

The datasets used and/or analyzed during the present study are available from the corresponding author upon reasonable request.

\section{Authors' contributions}

YY, WZ, TL and JQH wrote the paper and conceived and designed the experiments. XZha collected the data, and QZ and XZho analyzed the data. YY and JY obtained the results and validated them. YY, WZ and TL contributed to drafting the manuscript. All authors have read and approved the final published version of this manuscript.

\section{Ethics approval and consent to participate}

The present study was approved by the Ethics Committee of Hunan University of Chinese Medicine (Changsha, China) and conducted in accordance with the Laboratory animal-Requirements of Environment and Housing Facilities Guidelines (approval no. GB 14925-2010).

\section{Patient consent for publication}

Not applicable.

\section{Competing interests}

The authors declare that they have no competing interests. 


\section{References}

1. Kristal AR, Arnold KB, Schenk JM, Neuhouser ML, Goodman P, Penson DF and Thompson IM: Dietary patterns, supplement use, and the risk of symptomatic benign prostatic hyperplasia: Results from the prostate cancer prevention trial. Am J Epidemiol 167: 925-934, 2008

2. De Nunzio C, Kramer G, Marberger M, Montironi R, Nelson W, Schröder F, Sciarra A and Tubaro A: The controversial relationship between benign prostatic hyperplasia and prostate cancer: The role of inflammation. Eur Urol 60: 106-117, 2011.

3. McVary KT, Roehrborn CG, Avins AL, Barry MJ,Bruskewitz RC, Donnell RF, Foster HE Jr, Gonzalez CM, Kaplan SA, Penson DF, et al: Update on AUA guideline on the management of benign prostatic hyperplasia. J Urol 185: 1793-1803, 2011.

4. Neuhouser ML, Schenk J, Song YJ, Tangen CM, Goodman PJ, Pollak M, Penson DF, Thompson IM and Kristal AR: Insulin-like growth factor-I, insulin-like growth factor binding protein-3 and risk of benign prostate hyperplasia in the prostate cancer prevention trial. Prostate 68: 1477-1486, 2008.

5. Kaplan SA, Walmsley K and Te AE: Tolterodine extended release attenuates lower urinary tract symptoms in men with benign prostatic hyperplasia. J Urol 174: 2273-2275 discussion 2275-2276, 2005.

6. Keehn A, Taylor J and Lowe FC: Phytotherapy for benign prostatic hyperplasia. Curr Urol Rep 17: 53, 2016.

7. OkCY,Singh RR and Vega F: Aberrant activation of the hedgehog signaling pathway in malignant hematological neoplasms. Am J Pathol 180: 2-11, 2012.

8. Yoo YA, Kang MH, Kim JS and Oh SC: Sonic hedgehog signaling promotes motility and invasiveness of gastric cancer cells through TGF-beta-mediated activation of the ALK5-Smad 3 pathway. Carcinogenesis 29: 480-490, 2008.

9. Chen Q, Gao G and Luo S: Hedgehog signaling pathway and ovarian cancer. Chin J Cancer Res 25: 346-353, 2013.

10. Taylor R, Long J, Yoon JW, Childs R, Sylvestersen KB, Nielsen ML, Leong KF, Iannaccone S, Walterhouse DO, Robbins DJ and Iannaccone P: Regulation of GLI1 by cis DNA elements and epigenetic marks. DNA Repair (Amst) 79: 10-21, 2019.

11. Skoda AM, Simovic D, Karin V, Kardum V, Vranic S and Serman L: The role of the Hedgehog signaling pathway in cancer: A comprehensive review. Bosn J Basic Med Sci 18: 8-20, 2018.

12. Bar EE, Chaudhry A, Lin A, Fan X, Schreck K, Matsui W, Piccirillo S, Vescovi AL, DiMeco F, Olivi A and Eberhart CG: Cyclopamine-mediated hedgehog pathway inhibition depletes stem-like cancer cells in glioblastoma. Stem Cells 25: 2524-2533, 2007.

13. Kumar SK, Roy I, Anchoori RK, Fazli S, Maitra A, Beachy PA and Khan SR: Targeted inhibition of hedgehog signaling by cyclopamine prodrugs for advanced prostate cancer. Bioorg Med Chem 16: 2764-2768, 2008

14. Atkins D, Reiffen KA, Tegtmeier CL, Winther H, Bonato MS and Störkel S: Immunohistochemical detection of EGFR in paraffin-embedded tumor tissues: Variation in staining intensity due to choice of fixative and storage time of tissue sections. J Histochem Cytochem 52: 893-901, 2004.

15. Zhang X, Harrington N, Moraes RC, Wu MF, Hilsenbeck SG and Lewis MT: Cyclopamine inhibition of human breast cancer cell growth independent of Smoothened (Smo). Breast Cancer Res Treat 115: 505-521, 2009.

16. Slusarz A, Shenouda NS, Sakla MS, Drenkhahn SK, Narula AS, MacDonald RS, Besch-Williford CL and Lubahn DB: Common botanical compounds inhibit the hedgehog signaling pathway in prostate cancer. Cancer Res 70: 3382-3390, 2010

17. Chen JK, Taipale J, Cooper MK and Beachy PA: Inhibition of Hedgehog signaling by direct binding of cyclopamine to Smoothened. Genes Dev 16: 2743-2748, 2002.

18. Palumbo A, Casanova LM, Corrêa MFP, Da Costa NM, Nasciutti LE and Costa SS: Potential therapeutic effects of underground parts of Kalanchoe gastonis-bonnieri on benign prostatic hyperplasia. Evid Based Complement Alternat Med 2019: 6340757, 2019

19. Kogan-Sakin I, Cohen M, Paland N, Madar S, Solomon H, Molchadsky A, Brosh R, Buganim Y, Goldfinger N, Klocker H, et al: Prostate stromal cells produce CXCL-1, CXCL-2, CXCL-3 and IL-8 in response to epithelia-secreted IL-1. Carcinogenesis 30: 698-705, 2009.
20. Liu XY, Liu X, Xu L, Gui B, Yang QY, Yan JY and Sun ZY: A mathematical model for predicting putative association between $\mathrm{E} 2 / \mathrm{T}$ ratio and the development of benign prostate hyperplasia in rats. Biol Reprod 100: 133-138, 2019.

21. Livak KJ and Schmittgen TD: Analysis of relative gene expression data using real-time quantitative PCR and the 2(-Delta Delta C(T)) method. Methods 25: 402-408, 2001.

22. Shaw A and Bushman W: Hedgehog signaling in the prostate. J Urol 177: 832-838, 2007

23. Wang L, Yang JR, Yang LY and Liu ZT: Chronic inflammation in benign prostatic hyperplasia: Implications for therapy. Med Hypotheses 70: 1021-1023, 2008.

24. Kobayashi S, Tomiyama Y, Tatemichi S, Hoyano Y, Kobayashi M and Yamazaki Y: Effects of silodosin and tamsulosin on the urethra and cardiovascular system in young and old dogs with benign prostatic hyperplasia. Eur J Pharmacol 613: 135-140, 2009.

25. Adisa JO, Egbujo EC, Ibrahim B, Musa B and Madukwe J: Expression of some selected cytokeratins and Ki67 protein in prostatic tumor: Can these be used as tumor markers. Pan Afr Med J 20: 46, 2015.

26. Seligson DB, Yu H, Tze S, Said J, Pantuck AJ, Cohen P and Lee KW: IGFBP-3 nuclear localization predicts human prostate cancer recurrence. Horm Cancer 4: 12-23, 2013.

27. Fonseca-Alves CE, Kobayashi PE, Palmieri C and Laufer-Amorim R: Investigation of c-KIT and Ki67 expression in normal, preneoplastic and neoplastic canine prostate. BMC Vet Res 13: 380, 2017

28. Zheng H, Xu W, Lin J, Peng J and Hong Z: Qianliening capsule treats benign prostatic hyperplasia via induction of prostatic cell apoptosis. Mol Med Rep 7: 848-854, 2013.

29. Vezina CM and Bushman AW: Hedgehog signaling in prostate growth and benign prostate hyperplasia. Curr Urol Rep 8: 275-280, 2007.

30. Wang X, Fan G, Wei F, Bu Y and Huang W: Hyperoside protects rat ovarian granulosa cells against hydrogen peroxide-induced injury by sonic hedgehog signaling pathway. Chem Biol Interact 310: 108759, 2019.

31. Sharma A,DeR,Javed S, Srinivasan R,Pal A and Bhattacharyya S: Sonic hedgehog pathway activation regulates cervical cancer stem cell characteristics during epithelial to mesenchymal transition. J Cell Physiol Feb. 4, (Epub ahead of print).

32. Penna G, Fibbi B, Amuchastegui S, Corsiero E, Laverny G, Silvestrini E, Chavalmane A, Morelli A, Sarchielli E, Vannelli GB, et al: The vitamin D receptor agonist elocalcitol inhibits IL-8-dependent benign prostatic hyperplasia stromal cell proliferation and inflammatory response by targeting the RhoA/Rho kinase and NF-kappaB pathways. Prostate 69: 480-493, 2009.

33. Oue T, Yoneda A, Uehara S, Yamanaka H and Fukuzawa M: Increased expression of the hedgehog signaling pathway in pediatric solid malignancies. J Pediatr Surg 45: 387-392, 2010.

34. Lin J, Zhou J, Xu W, Hong Z and Peng J: Qianliening capsule inhibits benign prostatic hyperplasia angiogenesis via the HIF-1 $\alpha$ signaling pathway. Exp Ther Med 8: 118-124, 2014.

35. Iacopino F, Angelucci C, Lama G, Zelano G, La Torre G, D'Addessi A, Giovannini C, Bertaccini A, Macaluso MP, Martorana G and Sica G: Apoptosis-related gene expression in benign prostatic hyperplasia and prostate carcinoma. Anticancer Res 26: 1849-1854, 2006

36. Shariat SF, Ashfaq R, Roehrborn CG, Slawin KM and Lotan Y: Expression of survivin and apoptotic biomarkers in benign prostatic hyperplasia. J Urol 174: 2046-2050, 2005.

37. Shum CF, Lau W and Teo CPC: Medical therapy for clinical benign prostatic hyperplasia: $\alpha-1$ antagonists, $5 \alpha$ reductase inhibitors and their combination. Asian J Urol 4: 185-190, 2017.

38. Zhang G, Zhu F, Han G, Li Z, Yu Q, Li Z and Li J: Silencing of URG11 expression inhibits the proliferation and epithelial-mesenchymal transition in benign prostatic hyperplasia cells via the RhoA/ROCK1 pathway. Mol Med Rep 18: 391-398, 2018.

39. Wang Z, Xiao X, Ge R, Li J, Johnson CW, Rassoulian C and Olumi AF: Metformin inhibits the proliferation of benign prostatic epithelial cells. PLoS One 12: e0173335, 2017.

This work is licensed under a Creative Commons Attribution-NonCommercial-NoDerivatives 4.0 International (CC BY-NC-ND 4.0) License. 